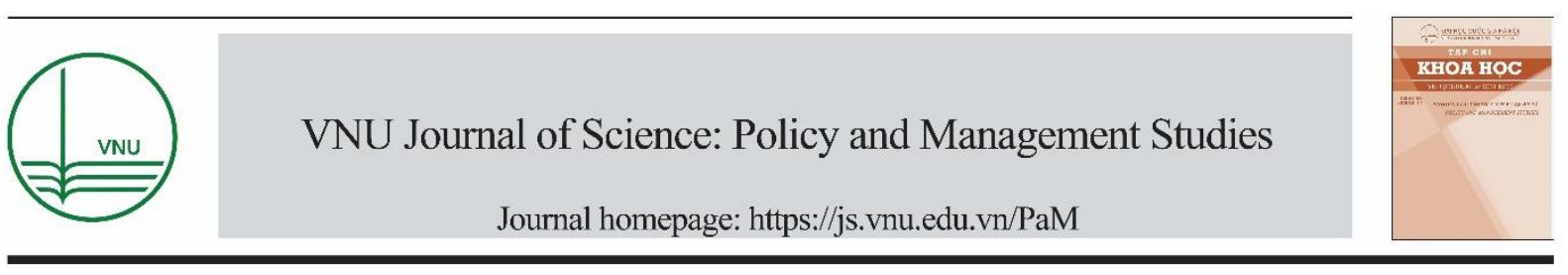

Original Article

\title{
Estimation of Tourists' Willingness to Pay in Ba Vi National Park: Choice Experiment Method
}

\author{
Nguyen Van Hieu ${ }^{1}$, Nguyen Hoang Nam,, Pham Van Trung ${ }^{3}$, Tran Minh Tuan \\ ${ }^{I}$ Capacity Development Centre for Environment and Natural Resources (CEN), \\ Indochina Plaza, 241 Xuan Thuy, Cau Giay, Hanoi, Vietnam \\ ${ }^{2}$ Institute of Strategy and Policy on Natural Resources and Environment, \\ 479 Hoang Quoc Viet, Cau Giay, Hanoi, Vietnam \\ ${ }^{3}$ Vietnam Forest Protection and Development Fund, Building A5, \\ 10 Nguyen Cong Hoan, Ba Dinh, Hanoi, Vietnam
}

Received 25 October 2019

Revised 23 December 2019; Accepted 24 December 2019

\begin{abstract}
Payment for forest environmental services is one of Vietnam's most successful policies in socializing forest protection in particular and environmental protection in general. However, the application of this policy in the field of tourism is limited. This study employs Choice Experiment Method to estimate tourists' willingness to pay in order to provide a scientific basis for the application of this policy in Ba Vi National Park. The results show that $74 \%$ of tourists agreed with an increase in the entrance fee and in the room rate to contribute to the implementation of the policy. Specifically, tourists were willing to pay roughly VND 37,000 more (equivalent to $61 \%$ of the current rate) for the entrance and roughly VND 181,000 (equivalent to $24 \%$ of the average rate) as an increase in the room rate.
\end{abstract}

Keywords: Willingness to pay, Choice Experiment method, Ba Vi National Park, payment for environmental services.

\footnotetext{
* Corresponding author.

E-mail address: nguyenhoangnam275@gmail.com
}

https://doi.org/10.25073/2588-1116/vnupam.4199 


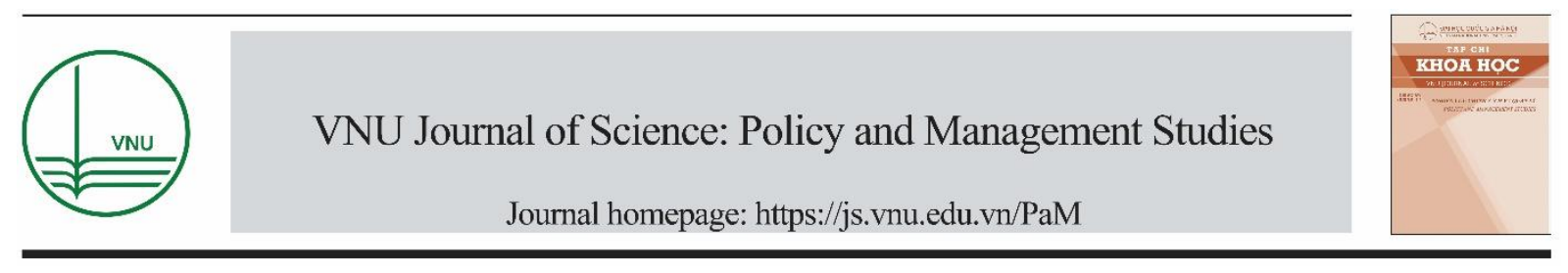

\title{
Ước lượng mức sẵn lòng chi trả của khách du lịch tại Vườn quốc gia Ba Vì: Phương pháp thực nghiệm lựa chọn
}

\author{
Nguyễn Văn Hiếu ${ }^{1}$, Nguyễn Hoàng Nam 2,*, Phạm Văn Trung³, Trần Minh Tuấn² \\ ${ }^{1}$ Trung tâm Phát triển Nguồn nhân lực Tài nguyên và Môi trường (CEN), \\ Tầng 6, Tòa nhà Indochina Plaza, 241 Xuân Thủy, Cầu Giấy, Hà Nội, Việt Nam \\ ${ }^{2}$ Viện Chiến lược Chính sách Tài nguyên và Môi truò̀ng, \\ 479 Hoàng Quốc Việt, Cầu Giấy, Hà Nội, Việt Nam
}

${ }^{3}$ Quỹ Bảo vệ và Phát triển rùng Việt Nam, Nhà A5, số 10 Nguyễn Công Hoan, Ba Đình, Hà Nội, Việt Nam

Nhận ngày 25 tháng 10 năm 2019

Chỉnh sửa ngày 23 tháng 12 năm 2019; Chấp nhận đăng ngày 24 tháng 12 năm 2019

\begin{abstract}
Tóm tắt: Chi trả dịch vụ môi trường rừng là một trong những chính sách thành công nổi bật của Việt Nam trong việc xã hội hóa công tác bảo vệ và phát triển rừng nói riêng và bảo vệ tài nguyên môi trường nói chung. Tuy nhiên, việc áp dụng chính sách này trong lĩnh vực du lịch còn nhiều hạn chế. Nghiên cứu này sử dụng phương pháp Thực nghiệm lựa chọn để ước lượng mức sẵn lòng chi trả của khách du lịch, nhằm cung cấp thêm cơ sở khoa học cho việc mở rộng áp dụng chính sách tại vườn quốc gia $\mathrm{Ba}$ Vì. Kết quả, $74 \%$ khách du lịch đồng thuận với việc tăng giá vé thăm quan và tăng giá phòng lưu trú để chung tay thực hiện chính sách Chi trả dịch vụ môi trường rừng. Mức sẵn lòng chi trả tương ứng của khách du lịch cho việc tăng giá là 37.000 đồng (bằng $61 \%$ giá vé vào cổng hiện tại) và 181.000 đồng (bằng $24 \%$ trung bình giá phòng hiện tại).
\end{abstract}

Tù khóa: Sẵn lòng chi trả, Phương pháp thực nghiệm lựa chọn, Vườn quốc gia Ba Vì, Chi trả dịch vụ môi trường.

\section{Mở đầu}

Giống như nhiều quốc gia khác trên thế giới, mặc dù diện tích rừng nói chung của Việt Nam có tăng trong khoảng hơn hai thập kỷ gần đây, nhưng diện tích rừng tự nhiên và chất lượng rừng đang có xu hướng suy giảm [1]. Theo công bố hiện trạng rừng toàn quốc năm 2017 , diện tích rừng tự nhiên đã giảm 5.726 ha so với năm 2016 . Trong số rừng tự nhiên còn lại, chỉ còn khoảng $86 \%$ là rừng gố (còn lại là rừng tre nứa thuần, rừng hỗn hợp và rừng cau dừa), và cũng chỉ $8,7 \%$

\footnotetext{
*Tác giả liên hệ.

Địa chi email: nguyenhoangnam275@gmail.com

https://doi.org/10.25073/2588-1116/vnupam.4199
} 
của diện tích rừng gỗ đó là rừng giàu [2]. Sự suy giảm chất lượng rừng có nguyên nhân từ các hoạt động phát triển kinh tế thiếu bền vững và do kinh phí cho hoạt động lâm nghiệp còn hạn chế $[3,4]$. Một số nghiên cứu gần đây đã chỉ ra rằng việc cải thiện số lượng và chất lượng rừng có thể đạt được nếu những người bảo vệ và phát triển rừng (các chủ rừng và các hộ nhận khoán bảo vệ rừng) nhận được khoản chi trả phù hợp với các dịch vụ hệ sinh thái mà họ đang bảo vệ và phát triển $[5$, 6]. Đó chính là lý do ra đời chính sách Chi trả dịch vụ môi trường rừng (DVMTR), dựa trên giao dịch giữa bên mua (bên sử dụng các DVMTR) và bên bán (bên giúp duy trì và phát triển các DVMTR), trên cơ sở những nguyên tắc về quản lý tài nguyên thiên nhiên nhằm duy trì và cải thiện các DVMTR [7].

Chính sách chi trả DVMTR tại Việt Nam được bắt đầu triển khai từ ngày 01 tháng 01 năm 2011 theo Nghị định 99/2010/NĐ-CP của Chính phủ. Điểm quan trọng của chính sách này là tiền DVMTR không thu về ngân sách trung ương mà được chi trả ngay tại địa phương cho những người trồng và bảo vệ rừng. Sau 10 năm tổ chức hoạt động Quỹ Bảo vệ và phát triển rừng (20082018), gắn với 8 năm triển khai thực hiện chính sách chi trả DVMTR (2011-2018), các Quỹ Bảo vệ và Phát triển rừng đã được thiết lập tại 44 tỉnh, với tổng tiền DVMTR thu được trên toàn quốc đạt hơn 10.000 tỷ đồng (bình quân hơn 1.300 tỷ đồng/năm, đóng góp $22 \%$ kinh phí của toàn ngành lâm nghiệp), giúp bảo vệ hơn 5,8 triệu ha rừng (chiếm $40,23 \%$ tổng diện tích rừng toàn quốc) và đặc biệt đã hỗ trợ kinh phí quản lý bảo vệ rừng cho các chủ rừng và hơn 410.000 hộ nhận khoán bảo vệ rừng [8]. Tới nay, chính sách chi trả DVMTR đã được đưa vào Luật Lâm nghiệp 2017 và được tiếp nối bởi Nghị định 156/2018/NĐ-CP ngày 16/11/2018 của Chính phủ quy định chi tiết thi hành một số điều của Luật Lâm nghiệp.

Một trong 5 DVMTR cần thực hiện chi trả đã được quy định tại Điều 61 của Luật Lâm nghiệp 2017 là "Bảo vệ cảnh quan tụ nhiên và bảo tồn đa dạng sinh học của các hệ sinh thái rùng phuc vu cho kinh doanh dịch vu du lịch". Đặc biệt, Khoản 4, Điều 11 của Nghị Định
99/2010/NĐ-CP trước đây quy định các cá nhân, cơ sở kinh doanh dịch vụ du lịch hưởng lợi từ rừng phải chi trả từ $1-2 \%$ doanh thu; và đến nay tại khoản 4 Điều 59 Nghị định 156/2018/NĐ-CP quy định mức chi trả tối thiểu là $1 \%$ trên tổng doanh thu thực hiện trong kỳ. Theo đó, Việt Nam là một trong những quốc gia đầu tiên trên thế giới quy định mức chi trả DVMTR đối với hoạt động kinh doanh du lịch [9]. Tuy nhiên, việc áp dụng chính sách này trên thực tế vẫn gặp nhiều khó khăn và khó được mở rộng trên phạm vi toàn quốc [10]. Một trong số các khó khăn là xác định mức chi trả DVMTR sao cho có tính thuyết phục cao với các cơ sở kinh doanh du lịch $[11,12]$.

Nghiên cứu về cơ chế chi trả DVMTR trong lĩnh vực du lịch tại Lào Cai và Thừa Thiên Huế, tác giả Nguyễn Hoàng Nam [13] và Nguyễn Công Thành [14] đều chỉ ra rằng mặc dù theo Khoản 4, Điều 4, Nghị định 99/2010 NĐ-CP (và sau này là Khoản 2 điều 63 của Luật Lâm nghiệp 2017) quy định đối tượng phải chi trả DVMTR trong lĩnh vực du lịch bao gồm các "tổ chức, cá nhân kinh doanh dịch vụ du lịch sinh thái, nghỉ dưỡng, giải trí”, khách du lịch tham gia các hoạt động du lịch dựa vào rừng không phải là đối tượng phải chi trả. Tuy nhiên, khoản 4 , Điều 5 của Nghị định 99/2010/NĐ-CP (và sau này là Khoản 4 điều 62 của Luật Lâm nghiệp 2017) cho phép các cơ sở kinh doanh du lịch có thể hạch toán tiền chi trả DVMTR vào trong giá thành. Theo đó, các cơ sở này sẽ cân nhắc việc tăng giá theo sự co giãn của đường cầu của khách du lịch. Vì thế, các tác giả này đã phân tích rằng mức sẵn lòng chi trả (Willingness To Pay - WTP) của khách du lịch là mối quan tâm hàng đầu của các cơ sở kinh doanh dịch vụ du lịch khi quyết định tham gia thực hiện chính sách chi trả DVMTR. Cụ thể, họ muốn hạn chế ảnh hưởng tiêu cực của việc tăng giá dịch vụ tới lượng khách và tới kết quả kinh doanh của mình. Do đó, việc ước lượng mức WTP của khách du lịch là cần thiết.

Ngoài $\mathrm{ra}$, việc thực thi chi trả DVMTR cần được áp dụng với đúng đối tượng hưởng lợi từ dịch vụ rừng và đảm bảo tránh trùng lặp trong khi thu. Theo đó, tác giả Nguyễn Hoàng Nam [13] cũng đề xuất rằng việc chi trả chỉ nên áp 
dụng với các hoạt động kinh doanh lưu trú và bán vé tham quan vào các khu thắng cảnh rừng. Đề xuất này đã được chấp nhận triển khai trên thực tế tại tỉnh Lào Cai. Vì vậy, trong nghiên cứu này, 2 đối tượng bao gồm khách tham quan và khách lưu trú được lựa chọn nghiên cứu về mức giá sẵn lòng trả đối với việc tăng giá vé vào cổng và giá phòng lưu trú khi thực hiện chính sách chi trả DVMTR.

\section{2. Địa điểm nghiên cứu}

Vườn Quốc gia (VQG) Ba Vì nằm trên địa giới hành chính của 16 xã thuộc 3 huyện của thành phố Hà Nội và 2 huyện của tỉnh Hòa Bình. VQG có tổng diện tích 9.704,35 ha, cách trung tâm thủ đô Hà Nội 60 km về phía Tây [15].

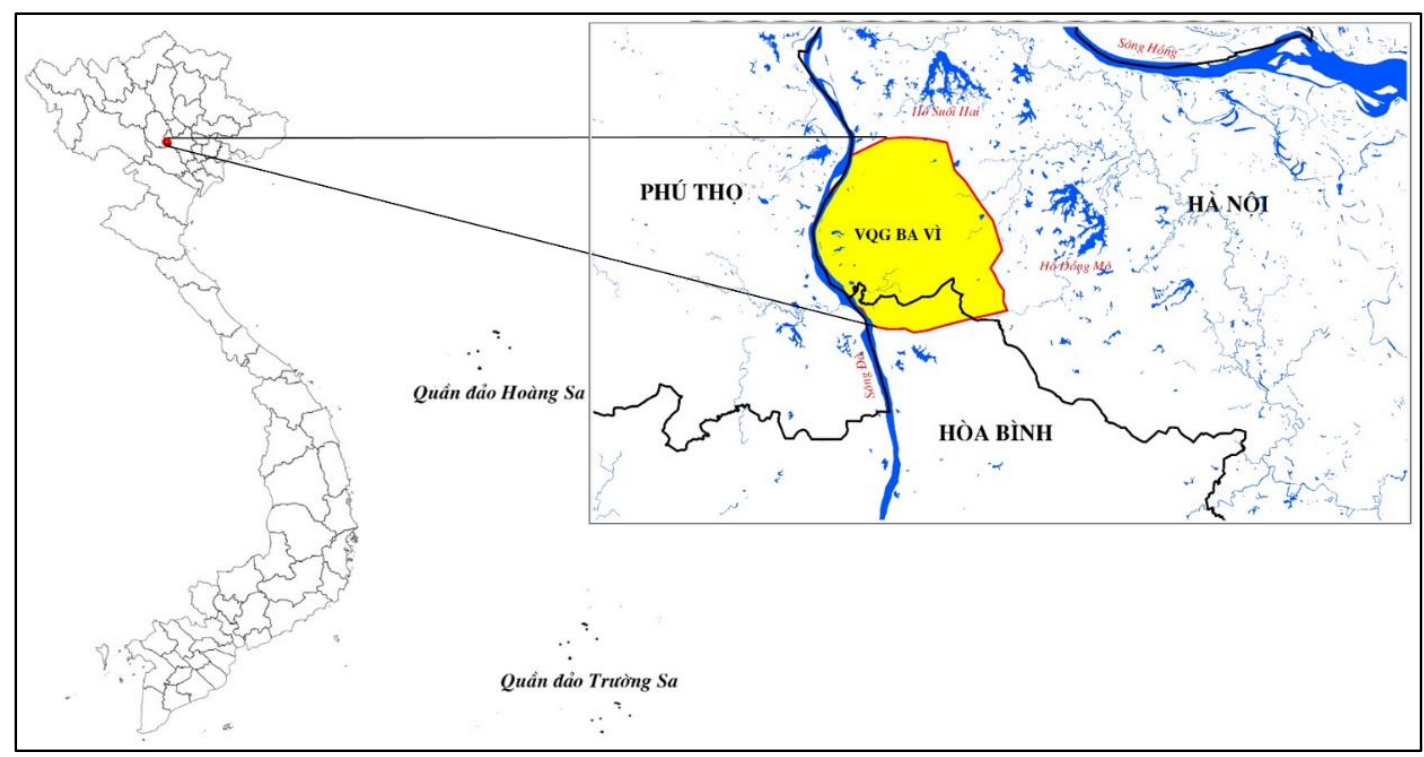

Hình 1. Vị trí Vườn Quốc Gia Ba Vì.

Nguồn: Trung tâm Giáo dục môi trường và Dịch vụ, Vườn Quốc gia Ba Vì (2017) [16].

Hiện nay, VQG Ba Vì là một trong những điểm đến ưa thích của khách du lịch trong nước, với 421.182 khách du lịch năm 2018 và tốc độ tăng trưởng trung bình khoảng 31\%/năm [17]. Hoạt động du lịch tại VQG chủ yếu là du lịch sinh thái, du lịch nghỉ dưỡng dựa vào rừng, cho thấy tiềm năng rất lớn để áp dụng chính sách chi trả DVMTR.

\section{Phương pháp nghiên cứu}

\subsection{Phuơng pháp Thưc nghiệm lựa chọn}

Phương pháp Thực nghiệm lựa chọn (Choice Experiment - $\mathrm{CE}$ ) hay Mô hình lựa chọn (Choice Modelling) là một phương pháp lượng giá thuộc nhóm Phát biểu sự ưa thích (Stated Preferences) [18]. Một phương pháp khác thuộc nhóm này cũng được sử dụng rất phổ biến là phương pháp Đánh giá ngẫu nhiên (Contingent Valuation Method - CVM). Tuy nhiên, phương pháp CE thường được ưa dùng hơn trong trường hợp cần tăng mức độ chính xác của ước lượng WTP [19]. Cơ sở của phương pháp này là tạo điều kiện để người trả lời phân tích mức WTP của mình được hình thành do các thuộc tính cụ thể nào, mức WTP cho mỗi thuộc tính đó là bao nhiêu, nhờ đó thu được được các câu trả lời WTP chính xác hơn cách hỏi thông thường của CVM. Đặc biệt, các mô hình phân tích kết quả phỏng vấn của $\mathrm{CE}$ cũng phức tạp hơn, giúp xác định rõ độ tin cậy hơn cách phân tích của CVM. 
Trong phương pháp $\mathrm{CE}$, việc xác định các thuộc tính và các cấp độ của các thuộc tính đó là rất quan trọng để đảm bảo sự thành công của phương pháp và mức độ chính xác của kết quả [20-22]. Vì thế, nghiên cứu này đã thực hiện một cuộc khảo sát sơ bộ, với 30 khách du lịch ngẫu nhiên tại VQG Ba Vì. Theo đó, 11 thuộc tính, là những lợi ích mà chính sách chi trả DVMTR có thể đem lại, đã được đưa ra để người trả lời lựa chọn (Hình 2). Kết quả, 3 thuộc tính quan trọng được lựa chọn nhiều nhất là: (1) Tăng thu nhập cho các hộ tham gia bảo vệ rừng, từ đó làm tăng chất lượng bảo vệ rừng; (2) Trồng rừng tại những nơi đất trống không có rừng và (3) Bảo tồn các loài động, thực vật quý hiếm. Từ đó, 3 thuộc tính này cùng với các mức thay đổi giá vé được sử dụng để thiết kế các lựa chọn của CE.

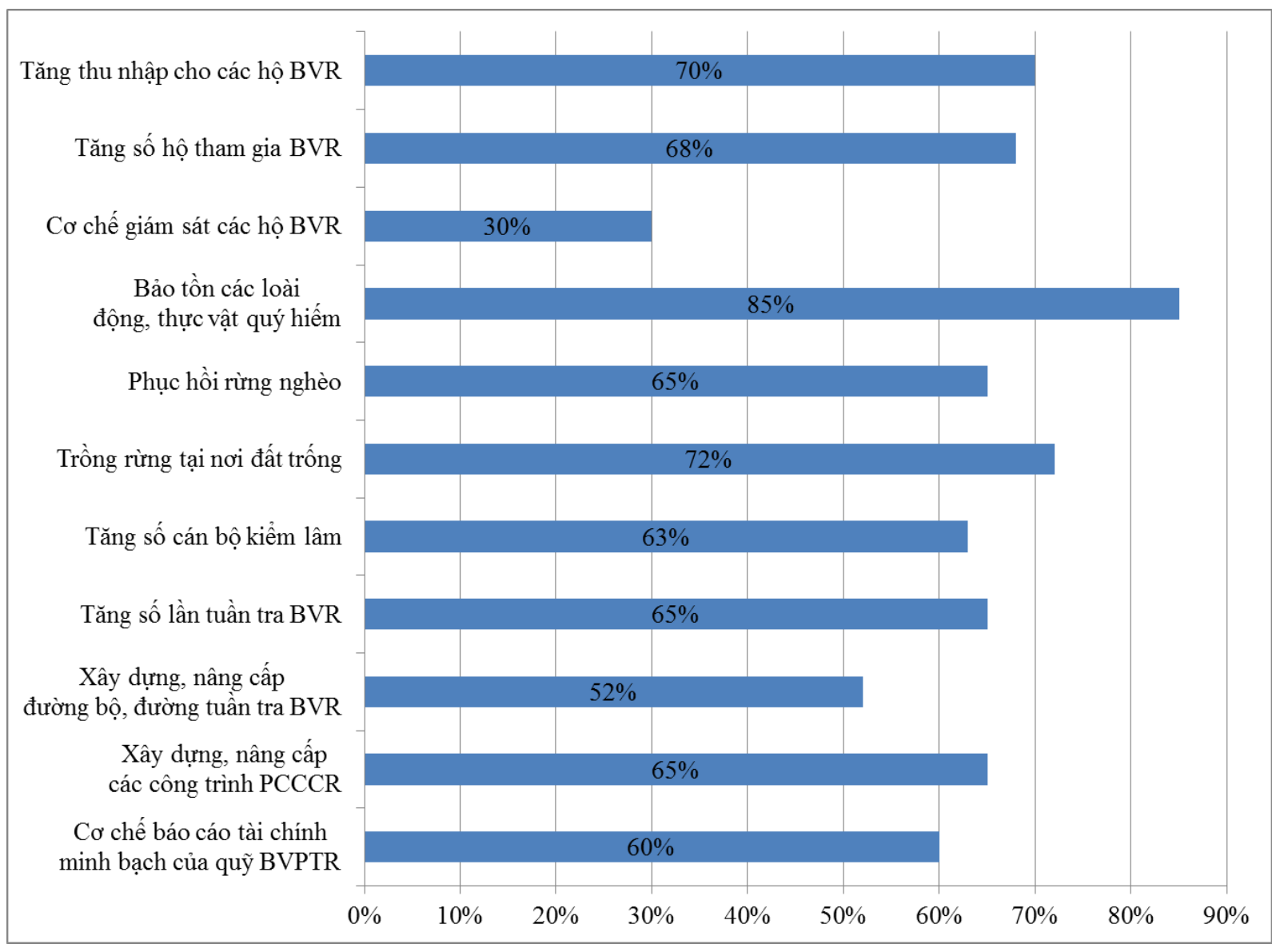

Hình 2. Kết quả phỏng vấn điều tra về các thuộc tính quan trọng của chính sách chi trả DVMTR tại VQG Ba Vì.

Tiếp theo đó, các cấp độ của các thuộc tính được xác định dựa trên kết quả khảo sát ý kiến khách du lịch, hiện trạng hoạt động của công ty du lịch tại VQG Ba Vì, đồng thời dựa trên việc phân tích các báo cáo hiện trạng, định hướng phát triển của VQG $\mathrm{Ba}$ Vì và ý kiến chuyên gia tại VQG Ba Vì. Lưu ý rằng, yêu cầu kỹ thuật đối với mức tăng giá cao nhất là phải đủ lớn để mức tiêu thụ tương ứng tại mức giá đó gần bằng 0 ; vì vậy, hai mức giá 40.000 đồng (mức tăng giá vé tham quan) và 250.000 đồng (mức tăng giá phòng lưu trú) đều lớn hơn mức sẵn lòng chi trả của khách du lịch đã khảo sát trong cuộc khảo sát sơ bộ. Các thuộc tính và các cấp độ tương ứng được thể hiện ở Bảng 1 . 
Bảng 1. Các thuộc tính và các cấp độ

\begin{tabular}{|c|c|}
\hline THUỘC TÍNH & CÁC CẤP ĐỘ \\
\hline Mức TĂNG GIÁ VÉ (VNĐ) & 0 (mức hiện tại);10.000; 20.000; 40.000 \\
\hline Mức TĂNG GIÁ PHÒNG (VNĐ) & 0 (mức hiện tại); 100.000; 150.000; 250.000 \\
\hline Tăng DIỆN TíCH rừng trồng thêm (ha) & 0 (mức hiện tại); 150; 200; 250 \\
\hline Tạo THU NHẬP BỀN VŨ'NG* & $\begin{array}{l}62 \text { hộ nhận khoán nhưng mức thu nhập chưa bền vững (mức } \\
\text { hiện taii); } 62 \text { hộ có thu nhập bền vững; } 93 \text { hộ có thu nhập bền } \\
\text { vững; } 124 \text { hộ có thu nhập bền vững }\end{array}$ \\
\hline Giám sát ĐA DẠNG SINH HỌC & Không thực hiện (mức hiện tại), Có thực hiện (2 năm 1 lần) \\
\hline
\end{tabular}

Ghi chú: * “Thu nhập bền vững” ở đây được hiểu là mức thu nhập đủ để các chủ rừng và các hộ nhận khoán bảo vệ rừng có thể đảm bảo cuộc sống gia đình, từ đó sẵn sàng dành toàn thời gian và gắn bó lâu dài với công việc này. Hiện nay, mỗi hộ tham gia nhận khoán bảo vệ rừng nhận được từ 1 triệu đến 2 triệu một tháng. Qua khảo sát của nghiên cứu này, để có thể gắn bó lâu dài với nghề rừng, thu nhập trung bình của mỗi hộ cần khoảng từ 40-50 triệu/năm. Nghiên cứu này lấy mức thu nhập 50 triệu/hộ/năm là mức thu nhập bền vững.

Từ Bảng 1 , các mức thay đổi của các thuộc tính được kết hợp với nhau để tạo nên các lựa chọn khác nhau về phương án thực thi (choice set). Nghiên cứu này sử dụng phần mềm Nlogit 5.0 để thiết kế các phương án thực thi. Theo đó, có 18 phương án cho khách tham quan và 18 phương án cho khách lưu trú. Các phương án này được chia thành 3 phiếu phỏng vấn cho khách tham quan và 3 phiếu phỏng vấn cho khách lưu trú, mỗi phiếu phỏng vấn gồm có 6 phương án. Ví dụ về một phương án thực thi (Mã số: 112210) được trình bày ở Hình 3 :

Câu 10. Khi so sánh tình hình Hiện trạng với Phương án thực thi (mã số: 112210), ông/bà có quyết định lựa chọn như thế nào?

\begin{tabular}{|c|c|c|}
\hline & HIỆN TRẠNG & Phương án THỰC THI \\
\hline Mức TĂNG GIÁ VÉ & 0 & 40 nghìn đồng \\
\hline $\begin{array}{l}\text { Tăng DIẸN TÍCH rừng trồng } \\
\text { thêm }\end{array}$ & 0 ha & 250 ha \\
\hline $\begin{array}{l}\text { TẠO THU NHẬP BÊN VŨ V́ } \\
\text { (Bào vệ rừng như là một nghề } \\
\text { chính, không cần làm thêm nghề } \\
\text { khác) cho các hộ nhận khoán bảo } \\
\text { vệ rừng }\end{array}$ & $\begin{array}{l}62 \text { hộ nhận khoán nhưng } \\
\text { mức thu nhập chưa bền } \\
\text { vững }\end{array}$ & $\begin{array}{c}93 \text { hộ có thu nhập bền } \\
\text { vững }\end{array}$ \\
\hline Giám sát ĐA DẠNG SINH HỌC & Không thực hiện & Không thực hiện \\
\hline
\end{tabular}

Đồng ý với Phương án thực thi trong câu hỏi

Không đồng ý với Phương án thực thi và đề nghị giữ nguyên hiện trạng

Hình 3. Ví dụ về một phương án thực thi. 
Kết quả của phiếu khảo sát chính thức được sử dụng để xây dựng hàm lợi ích $\left(U_{i}\right)$ mà khách du lịch được hưởng từ việc tham gia thực hiện chi trả DVMTR tại VQG Ba Vì. Hàm lợi ích này được ước lượng dưới dạng một hàm số của các thuộc tính phản ánh mức tăng giá dịch vụ và mức độ thực hiện hoạt động quản lý bảo vệ rừng như sau:

$$
U_{i}=\beta_{k} x_{k i}+\varepsilon_{i}
$$

Trong đó,

$U_{i}$ là lợi ích mà khách du lịch được hưởng từ việc tham gia thực hiện chính sách chi trả DVMTR tại VQG Ba Vì (theo đánh giá của chính họ);

$\beta_{k}$ là hệ số được ước lượng trong mô hình, giúp đánh giá ảnh hưởng của các thuộc tính;

$x_{k i}$ là các biến độc lập, chính là 4 thuộc tính, trong đó có 1 thuộc tính là mức tăng giá và 3 thuộc tính về các hoạt động quản lý bảo vệ rừng (Ví dụ một nhóm thuộc tính tại Hình 3);

$\varepsilon_{i}$ là thành phần ngẫu nhiên (yếu tố gây nhiễu mô hình).

Hàm lợi ích trong phương pháp CE được xây dựng xuất phát từ lý thuyết của Lancaster [23]. Theo đó, lợi ích của một hàng hóa/ dịch vụ bất kỳ là tổng sigma các lợi ích của các thuộc tính cấu tạo nên nó. Hàm lợi ích này ngoài phụ thuộc vào các đặc điểm (thuộc tính) của hàng hóa còn phụ thuộc vào đặc điểm kinh tế xã hội của người lựa chọn $[24,25]$. Theo đó, trên cơ sở lý thuyết hành vi, các lựa chọn sẽ được thực hiện sao cho tối đa hóa lợi ích cá nhân. Khi đối mặt với một loạt các lựa chọn, cá nhân $i$ sẽ chọn thuộc tính $j$ thay cho thuộc tính $\mathrm{k}$ nếu $\mathrm{U}_{\mathrm{ij}}>\mathrm{U}_{\mathrm{ik}}$ [26]. Dựa trên lý thuyết của Lancaster (1966), việc bóc tách hàng hóa/ dịch vụ thành các thuộc tính riêng lẻ giúp chúng ta hiểu được sự lựa chọn mà người trả lời phải đối mặt tại thời điểm lựa chọn. Nếu giá là một trong những thuộc tính được xem xét, tổng thặng dư tiêu dùng hay mức độ sẵn sàng chi trả (WTP) có thể được tính theo công thức sau [27]:

$$
W T P=\sum\left(\beta_{\text {attribute }} / \beta_{\text {income }(\text { cost })}\right)
$$

Trong đó,
WTP là mức sẵn lòng chi trả của du khách (đồng);

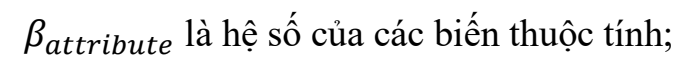

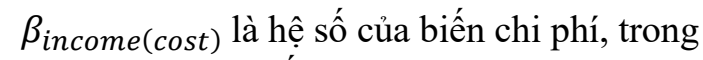
trường hợp này là biến tăng giá dịch vụ (giá vé tham quan và giá phòng lưu trú).

\subsection{Dũ liệu nghiên cứu}

Nghiên cứu này sử dụng cả dữ liệu thứ cấp và sơ cấp. Số liệu thứ cấp được thu thập từ các báo cáo chính thức của Ban quản lý VQG Ba Vì, Hạt kiểm lâm VQG Ba Vì, Trung tâm dịch vụ sinh thái và giáo dục môi trường của $\mathrm{VQG} B \mathrm{Ba}$ Vì và Công ty cổ phần đầu tư du lịch Pico Việt Nam. Các số liệu này được sử dụng để xác định các thuộc tính và các cấp độ tương ứng)

Dữ liệu sơ cấp được thu thập bằng phương pháp điều tra phỏng vấn trực tiếp dựa trên các phiếu phỏng vấn soạn sắn, bao gồm: Phiếu phỏng vấn sơ bộ (dùng để bổ sung thông tin cho việc xác định các thuộc tính) và Phiếu phỏng vấn chỉnh thức dùng để ước lượng mức sã̃n lòng chi trả của du khách theo phương pháp $\mathrm{CE}$.

Cỡ mẫu của nghiên cứu này được xác định theo công thức của Godden [28] như sau:

$$
\begin{gathered}
n(\text { infinite })=\frac{Z^{2} p(1-p)}{c^{2}} \\
n(\text { finite })=\frac{n(\text { infinite })}{1+\left(\frac{n(\text { infinite })-1}{\text { Pop }}\right)}
\end{gathered}
$$

Trong đó: 50.000;

$n$ (infinite) là cỡ mẫu với tổng thể lớn hơn

$n$ (finite) là cỡ mẫu với tổng thể xác định nhỏ hơn 50.000;

$Z$ là tham số thể hiện mức độ tin cậy, với $Z=1,96$ (tương đương 95\% độ tin cậy);

$p$ là xác suất đưa ra 1 lựa chọn, thường giả định là 0,5 ;

$c$ là sai số biên, chọn là $4,5 \%$;

Pop là số lượng tổng thể; Trung bình 3 năm gần nhất (năm 2016, 2017 và 2018), số lượt khách đến VQG Ba Vì là 421.182 [17]. 
Theo đó, cỡ mẫu cần có là 474. Với đặc điểm của phương pháp $\mathrm{CE}$, mỗi phiếu phỏng vấn trong nghiên cứu được thiết kế có 6 phương án lựa chọn, nên với cỡ mẫu là 474, nghiên cứu cần số phiếu phỏng vấn tối thiểu là 79 . Trên thực tế, 100 phiểu phỏng vấn đã được thực hiện và thu về được 83 phiếu phỏng vấn trả lời đầy đủ $(53$ khách tham quan và 30 khách vừa tham quan vừa lưu trú), đạt 498 phương án lựa chọn.

\section{Kết quả nghiên cứu}

Kết quả khảo sát cho thấy, mặc dù chính sách chi trả DVMTR đã được ban hành từ năm 2010 (Nghị định 99/2010/NĐ-CP), nhưng phần lớn khách du lịch (87\% tổng số du khách được khảo sát) không biết về chính sách này. Tuy nhiên, sau khi được giải thích về chính sách, 74\% số khách du lịch trả lời phỏng vấn cho rằng việc áp dụng rằng chính sách này là cần thiết trong bối cảnh hiện tại và sẵn sàng đóng góp để tăng cường hoạt bảo vệ rừng tại VQG Ba Vì thông qua việc chấp nhận tăng giá vé du lịch. Do đó, để chính sách chi trả sớm đi vào thực tế với sự đồng thuận cao từ các bên liên quan, công tác tuyên truyền về chính sách cần phải được đẩy mạnh và thực hiện trước.

Khi thực thi việc chi trả DVMTR, hoạt động quản lý bảo vệ rừng sẽ được tăng cường nhằm duy trì, cải thiện giá trị cảnh quan thiên nhiên và đa dạng sinh học rừng phục vụ hoạt động du lịch. Như vậy, với nhóm biến số độc lập bao gồm 3 biến số (thuộc tính), kết quả mô hình $\mathrm{CE}$ được trình bày trong Bảng 2 và Bảng 3 :

Bảng 2. Kết quả ước lượng mô hình lựa chọn của du khách khi giá vé tham quan thay đổi

\begin{tabular}{llll}
\hline Các biến & Hệ số $\beta$ & Sai số chuẩn & Giá trị $P$ \\
\hline Tăng giá vé tham quan & $-0,000036^{*}$ & 0,00001024 & 0,0003 \\
Tăng diện tích rừng trồng & 0,00139 & 0,0016509 & 0,3987 \\
Số hộ có thu nhập bền vững & $0,020204^{*}$ & 0,005501 & 0,0002 \\
$\begin{array}{l}\text { Thực hiện chương trình giám sát đa } \\
\text { dạng sinh học }\end{array}$ & $0,651739^{*}$ & 0,25262527 & 0,0099 \\
\hline
\end{tabular}

Ghi chú: * thể hiện mức ý nghĩa thống kê $1 \%$

Bảng 3. Kết quả ước lượng mô hình lựa chọn của du khách khi giá phòng lưu trú thay đổi

\begin{tabular}{llll}
\hline & Hệ số $\beta$ & Sai số chuẩn & Giá trị $P$ \\
\hline $\begin{array}{l}\text { Tăng giá phòng lưu trú } \\
\text { Tăng diện tích rừng trồng }\end{array}$ & $-0,00000676^{*}$ & 0,00000248 & 0,0064 \\
$\begin{array}{l}\text { Số hộ có thu nhập bền vững } \\
\begin{array}{l}\text { Thực hiện chương trình giám sát đa } \\
\text { dạng sinh học }\end{array}\end{array} 0^{0,000237}$ & $0,019437^{*}$ & 0,00261072 & 0,9275 \\
& $0,960355^{*}$ & 0,32626227 & 0,0055 \\
\end{tabular}

Ghi chú: * thể hiện mức ý nghĩa thống kê $1 \%$

Kết quả được thể hiện ở Bảng 2 và Bảng 3 đều chỉ ra rằng, dấu của hệ số ước lượng $\beta$ đều phù hợp với lý thuyết kinh tế, đó là khi giá tăng, những lựa chọn ủng hộ việc tăng giá nhằm thực thi chi trả DVMTR giảm. Khi hoạt động bảo vệ rừng được tăng cường, thể hiện qua: (i) Tăng diện tích rừng trồng; (ii) Số hộ có thu nhập bền vững và (iii) Thực hiện chương trình giám sát đa dạng sinh học (ĐDSH), thì sự ủng hộ của du khách tăng lên. Ngoại trừ biến "Tăng diện tích rừng trồng" trong mô hình về giá vé tham quan và giá phòng lưu trú không có ý nghĩa thống kê, nguyên nhân có thể do du khách quá yêu thích thuộc tính này, sự thay đổi các định mức trong các phương án của thuộc tính thay đổi không làm ảnh hưởng đến lựa chọn thuộc tính này của du 
khách. Các biến số độc lập còn lại cơ bản đều có ý nghĩa thống kê cao, phản ánh ảnh hưởng của các biến độc lập tới quyết định ủng hộ hay không ủng hộ của du khách là có ý nghĩa.

Sử dụng kết quả mô hình $\mathrm{CE}$, nếu chất lượng công tác bảo vệ và phát triển rừng được cải thiện khi thực hiện chính sách chi trả DVMTR, du khách sẵn sàng đóng góp thông qua việc tăng giá dịch vụ du lịch (bao gồm: vé vào VQG và giá phòng lưu trú). Sử dụng kết quả mô hình $\mathrm{CE}$, mức cao được ước tính dựa trên việc tăng cường hoạt động bảo vệ rừng được thực hiện ở mức cao (trồng thêm 250 ha, tạo thu nhập bền vững cho 124 hộ, có thực hiện chương trình giám sát ĐDSH). Mức thấp được ước tính dựa trên việc tăng cường hoạt động bảo vệ rừng được thực hiện ở mức thấp (trồng thêm 100 ha, tạo thu nhập bền vững cho 62 hộ, có thực hiện chương trình giám sát ĐDSH). Mức tăng giá dịch vụ du lịch tại VQG Ba Vì mà du khách có thể chấp nhận được ước lượng theo công thức sau:

$$
W T P=\frac{\beta_{\text {Foresta }}}{\beta_{\text {Ticket }}} F+\frac{\beta_{\text {Inc }}}{\beta_{\text {Ticket }}} H+\frac{\beta_{\text {Biod }}}{\beta_{\text {Tiket }}} \mathrm{T}
$$

Trong đó,

WTP là mức sẵn lòng trả của du khách (VNĐ);

$\beta_{\text {Forest } A}, \beta_{\text {Inc }}, \beta_{\text {Biod là hệ số ước lượng của }}$ biến tăng diện tích rừng trồng, số hộ có thu nhập bền vững và thực hiện chương trình giám sát ĐDSH;

$\beta_{\text {Ticket }}$ là hệ số ước lượng của biến tăng giá vé tham quan (hoặc tăng giá phòng); $F, H, T$ lần lượt là định mức của các thuộc tính tăng diện tích rừng trồng, số hộ có thu nhập bền vững và thực hiện chương trình giám sát ĐDSH. Kết quả tính toán được thể hiện trong Bảng 4.

Bảng 4. Mức sẵn lòng chi trả của du khách ước lượng theo phương pháp $\mathrm{CE}$

\begin{tabular}{lll}
\hline & Mức cao & Mức thấp \\
\hline $\begin{array}{l}\text { Mức tăng giá vé tham } \\
\text { quan cho 1 người (VNĐ) }\end{array}$ & $95.268,5$ & $37.831,2$ \\
\hline $\begin{array}{l}\text { Mức tăng giá phòng lưu } \\
\text { trú cho 1 phòng (VNĐ) }\end{array}$ & $365.129,6$ & $181.686,8$ \\
\hline
\end{tabular}

Kết quả tính toán cho thấy, mức tăng giá vé tham quan cho một người ở mức cao khoảng 95.000 đồng, mức thấp khoảng 37.000 đồng và mức tăng giá phòng lưu trú cho 1 phòng ở mức cao khoảng 365.000 đồng, mức thấp khoảng 181.000 đồng. Theo cách tiếp cận thận trọng, đặc biệt với các phương pháp dựa trên sự tuyên bố mức ưa thích trong tình huống giả định, giá trị nhỏ hơn nên được sử dụng.

Chi phí (tiền vé hoặc tiền phòng) của khách du lịch là khoản thu của cơ sở kinh doanh dịch vụ du lịch (bán vé tham quan hoặc dịch vụ lưu trú). Vì vậy, ước lượng về tỷ lệ phần trăm sẽ cho biết mức phần trăm tăng doanh thu nhờ tăng giá dịch vụ trong khoảng mức tăng mà khách du lịch chấp nhận. Với mức giá vé tham quan hiện tại tại VQG Ba Vì là 60.000 đồng/người, mức tăng giá vé tham quan du khách có thể chấp nhận tương đương khoảng $61 \%$ giá vé hiện tại. Với giá phòng lưu trú trung bình là 750.000 đồng/phòng/ngày, giá phòng tăng mà du khách có thể chấp nhận tương đương với $24 \%$ giá phòng hiện tại. Đây là kết quả quan trọng, là cơ sở thực tiễn và khoa học cho việc thực hiện chi trả DVMTR tại VQG Ba Vì.

Như vậy, kết quả về WTP của khách du lịch cho thấy các công ty du lịch hoàn toàn có thể yên tâm tham gia thực hiện chính sách chi trả DVMTR tại VQG Ba Vì, với mức chi trả theo Luật Lâm nghiệp là $1 \%$ doanh thu, ở đây giới hạn là doanh thu từ hoạt động bán vé và kinh doanh lưu trú. Khi áp dụng mức thu trên, với số lượng du khách năm 2018 là 421.182 người, giá vé trung bình 35.000 đồng/người, doanh thu ước tính từ chi trả DVMTR đối với hoạt động bán vé du lịch đạt khoảng 147,4 triệu đồng/nămm. Với số lượng khách lưu trú năm 2018 đạt 4.450 người, trung bình khách ở 2 người/phòng, thời gian lưu trú trung bình là 1,2 đêm, giá phòng trung bình 750.000/phòng/đêm, doanh thu thu ước tính từ chi trả DVMTR đối với hoạt động kinh doanh lưu trú đạt khoảng 20 triệu đồng/năm.

\section{Kết luận}

Sử dụng phương pháp Thực nghiệm chọn, nghiên cứu này đã ước lượng mức sẵn lòng chi 
trả của khách du lịch khi chính sách chi trả DVMTR được thực hiện tại VQG Ba Vì. Kết quả nghiên cứu cho thấy mức sẵn lòng chi trả của du khách thông qua việc tăng giá vé tham quan là 37.000 đồng/người (tương đương với $61 \%$ giá vé hiện tại) và 181.000 đồng/người thông qua việc tăng giá phòng lưu trú (tương đương với $24 \%$ giá phòng hiện tại). Đây cơ sở quan trọng để các công ty kinh doanh du lịch cân nhắc tham gia thực hiện chính sách khi thấy lợi ích của việc tham gia vào chính sách này. Đồng thời, kết quả nghiên cứu cũng là cơ sở giúp các nhà hoạch định chính sách đưa ra mức thu tối ưu, đảm bảo cơ sở khoa học, cơ sở pháp lý của chính sách chi trả DVMTR và cơ sở thực tiễn tại Vườn quốc gia Ba Vì. Với mức thu khuyến nghị trong nghiên cứu này là $1 \%$ tổng doanh thu từ hoạt động bán vé và kinh doanh lưu trú, tổng nguồn thu sẽ đạt trên 167.4 triệu đồng/năm.

Ngoài ra, ngay cả khi chính sách Chi trả DVMTR chưa được áp dụng tại VQG Ba Vì, các kết quả nghiên cứu này cũng có thể là thông tin tham khảo cho việc tăng giá vé thăm quan và giá phòng lưu trú, trong trường hợp các công ty du lịch có thể đầu tư để nâng cao chất lượng môi trường rừng, bao gồm: Tăng thu nhập cho các hộ tham gia bảo vệ rừng, từ đó làm tăng chất lượng bảo vệ rừng; Trồng rừng giúp tăng diện tích rừng và Bảo tồn các loài động, thực vật quý hiếm.

\section{Tài liệu tham khảo}

[1] CIFOR, Annual Report 2018: Forests Matter, 2018.[Online].Available: https://annualreport2018.cifor.org/getting-aheadof-climate-change/road-to-recovery-for-vietnamsforests/

[2] Ministry of Agriculture and Rural Development, Decision 1187/QD-BNN-TCLN: Decision on announcing the status of national forests in 2017 Hanoi, 2018, (In Vietnamese).

[3] Asian Development Bank, Scaling up Payments for Forest Environmental Services in Vietnam: Lessons and Insights from Quang Nam, Mandaluyong, Philippines, 2014.

[4] N.H. Nguyen, Cost-Benefit Analysis Of Climate Adaptation: A Case Study Of Mangrove Conservation And Reforestation In $\mathrm{Ca} \mathrm{Mau}$
Province, Vietnam, Journal of Mekong Societies 11 (2) (2015)19-43.

[5] T. Nguyen, C. Nguyen, P. Nguyen, T. Pham, D. Bonnardeaux, D. Riedel, Payment for forest environmental services: a case study on pilot implementation in Lam Dong Province, Vietnam 2006-2010, Winrock International, 2011.

[6] T.T.H. Tran, M. Zeller, D. Suhardiman, Payments for ecosystem services in Hoa Binh province, Vietnam: An institutional analysis, Ecosystem Services 22 (2016) 83-93.

[7] S. Wunder, Revisiting the concept of payments for environmental services, Ecological Economics 117 (2015) 234-243.

[8] Newsletter Payment for forest environmental services, No. 3/2018, VNFF, Hanoi, 2018 (in Vietnamese).

[9] K.D. Groot, Payments for environmental services (PES) from tourism, A realistic incentive to improve local livelihoods sustain forest landscapes in Viet Nam's northern highlands, Bogor, Indonesia, 2011.

[10] T.T. Pham, K. Bennett, T.P. Vu, J. Brunner, N. Le, D.T. Nguyen, Payments for forest environmental services in Vietnam: from policy to practice, 2013.

[11] Tran The Lien, Proposing mechanisms and policies for eco-tourism development in Vietnam National Parks and Nature Reserves, Proceedings of the Conference "Finalizing mechanisms and policies to promote Ecotourism activities associated with conservation work in Vietnam National Parks and Nature Reserves", Food and Agriculture Organization of the United Nations (FAO) and Vietnam National Park and Nature Reserves Association, Hanoi, 2011 (in Vietnamese).

[12] S.K. Pattanayak, S. Wunder, P. J. Ferraro, Show me the money: do payments supply environmental services in developing countries?, Review of environmental economics policy, 4 (2) (2010) 254-274.

[13] N.H. Nam, Study report: Economic valuation of ecosystem services to develop payment for forest environmental services mechanism on tourism in Lao Cai province, in Economic valuation of ecosystem services to develop payment for forest environmental services mechanism on industrial production and tourism in Lao Cai and Thua Thien Hue province, Asian Development Bank (ADB), Ed. Hanoi: ADB/TA-8592: iPFES (2016) 48-106.

[14] N.C. Thanh, Study report: Economic valuation of ecosystem services to develop payment for forest environmental services mechanism on tourism in Thua Thien Hue province, in Economic valuation of ecosystem services to develop payment for 
forest environmental services mechanism on industrial production and tourism in Lao Cai and Thua Thien Hue province, Asian Development Bank (ADB), Ed. Hanoi: ADB/TA-8592: iPFES, (2016)116-149.

[15] Ba Vi National Park Management Board, Report on forest management and protection results in 2018, directions for 2019, Hanoi, 2019 (in Vietnamese).

[16] Center for Environmental Education and Services, Travel Map of $\mathrm{Ba} \mathrm{Vi}$ National Park (in Vietnamese), Ba Vi National Park, 2017.

[17] Center for Ecological and Environmental Education, Tourism Results Report 2018, Hanoi, 2019(in Vietnamese).

[18] T.H. Tietenberg, L. Lewis, Environmental economics and policy (no. Sixth edition). Boston: Addison-Wesley (Pearson), 2010.

[19] P.A. Mahieu, H. Andersson, O. Beaumais, R. Crastes, F.C. Wolff, Is Choice Experiment Becoming more Popular than Contingent Valuation? A Systematic Review in Agriculture, Environment and Health, FAERE Working Paper, 2014.

[20] J. Coast et al., Using qualitative methods for attribute development for discrete choice experiments: issues and recommendations, Health economics, 21 (6) (2012) 730-741.

[21] D. Hensher, J.M. Rose, W.H. Greene, Applied Choice Analysis: A Primer, Cambridge University Press. United Kingdom, 2005.
[22] M. Ryan, A role for conjoint analysis in technology assessment in health care?, International journal of technology assessment in health care 15 (3) (1999) 443-457.

[23] K.J. Lancaster, A new approach to consumer theory, Journal of Political Economy 74 (2) (1966) 132-157.

[24] F. Boccia, D. Covino, P. Sarnacchiaro, Genetically modified food versus knowledge and fear: A Noumenic approach for consumer behaviour, Food Research International 111 (2018) 682-688.

[25] V. Caputo, R. M. Nayga Jr, R. Scarpa, Food miles or carbon emissions? Exploring labelling preference for food transport footprint with a stated choice study, Australian Journal of Agricultural Resource Economics 57 (4) (2013) 465-482.

[26] N. Mtimet, L.M. Albisu, Spanish wine consumer behavior: A choice experiment approach, Agribusiness: An International Journal, 22(3) (2006) 343-362.

[27] D. Chotikapanich, W. E. Griffiths, Carnarvon Gorge: a comment on the sensitivity of consumer surplus estimation, Australian Journal of Agricultural and Resource Economics 42 (3) (1998) 249-261.

[28] B. Godden, Sample size formulas, 2004. http://williamgodden.com/samplesizeformula.pdf (accessed 20 Dec, 2018). 